\title{
Sujeitos, saberes e práticas em circulação nas Jornadas Internacionais de Educação Física: tessituras e modelagens pedagógicas (Belo Horizonte, 1957-1962)
}

\author{
Cássia Danielle Monteiro Dias Lima* \\ Meily Assbú Linhales**
}

\begin{abstract}
Resumo: Este artigo aborda, numa perspectiva histórica, o tema da formação de professores de Educação Física a partir dos métodos, conteúdos e sujeitos em circulação nas Jornadas Internacionais de Educação Física, realizadas na cidade de Belo Horizonte, entre 1957 e 1962. Com base em fontes documentais e depoimentos, identificou-se uma Educação Física de contornos moralizadores, afiançada por prescrições religiosas, realçando preceitos de uma educação integral e humanista.
\end{abstract}

Palavras-chave: História da Educação Física. Formação de professores. Modelos pedagógicos.

\section{INTRODUÇÃo}

Entre 1957 e 1962, a cidade de Belo Horizonte sediou um conjunto de cursos de aperfeiçoamento técnico e pedagógico denominado Jornadas Internacionais de Educação Física. Objetivavam ampliar a formação de professores e instrutores que já atuavam em escolas e em praças de esporte, e também de estudantes de Educação Física na recém-inaugurada Escola de Educação Física de Minas Gerais. A partir desse tempo/lugar de práticas pedagógicas, este artigo aborda, em uma perspectiva histórica, a formação em Educação Física com base nos métodos, conteúdos e sujeitos em circulação nas Jornadas.

\footnotetext{
Universidade do Estado de Minas Gerais, Ibirité, MG, Brasil. E-mail: cassia.danielle@yahoo. com.br

"Curso de Educação Física, Universidade Federal de Minas Gerais, Belo Horizonte, MG, Brasil. E-mail: meily_linhales@yahoo.com.br
} 
Tais cursos adquiriram expressividade para a Educação Física mineira do período, modelando representações sobre a formação e o ensino desse componente curricular. Foram cinco edições, realizadas anualmente, com duração média de duas semanas cada. Na pesquisa, buscou-se conhecer os detalhes desses cursos: os professores organizadores e aqueles convidados a ministrar aulas, o perfil do público participante, a organização pedagógica, os apoios e sustentações políticas, os conteúdos de ensino selecionados para cada edição, entre outros. Pela análise desses elementos, foi possível identificar alguns projetos que modelaram pedagogicamente a Educação Física em Belo Horizonte, conhecer as entidades organizadoras das Jornadas e as ações daí decorrentes.

O estudo constitui parte de um programa de pesquisa intitulado "Modelos pedagógicos, formação docente e práticas escolares: o ensino da Educação Física em Belo Horizonte (1947-1977)" em curso no CEMEF - Centro de Memória da Educação Física, do Esporte e do Lazer, na UFMG. ${ }^{1}$ Nesse lugar institucional de pesquisa e de guarda documental, os estudos históricos sobre a formação de professores e sobre o próprio processo de constituição e afirmação do campo da Educação Física em Minas Gerais são alimentados pela riqueza de fontes custodiadas no Centro. Os pesquisadores envolvidos nos processos de organização documental tendem a se envolver na trama dos arquivos, extraindo daí perguntas originais de pesquisa. Foi esse o caso da pesquisa que abordou, de modo peculiar, as Jornadas Internacionais de Educação Física (LIMA, 2012).

O corpus documental constituído incluiu fontes de natureza variada, tais como jornais, fotografias, planos de aula, cadernos de planejamentos, anais e filme. No exercício de cruzamento de fontes, alguns depoimentos orais compuseram também as possibilidades interpretativas, pois consideramos relevante ouvir os relatos daqueles que, de alguma forma, participaram

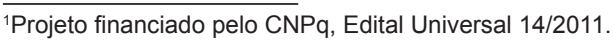

Movimento, Porto Alegre, v. 20, n. 4, p. 1499-1521, out./dez. de 2014. 
desse curso, dando visibilidade às suas interpretações singulares sobre a experiência e confirmando a premissa de que lembrança, esquecimento e reconstrução são escolhas de cada sujeito. As fontes impressas foram levadas às entrevistas, e essa opção metodológica nos permitiu compreender que os entrevistados exploram significados subjetivos sobre o vivido ao tratar daquilo que rememoram. Nessa seleção racional e afetiva, produzem um ponto de vista particular sobre o realizado (THOMPSON; FRISCH; HAMILTON, 2002).

Transformando a análise de fontes em uma escrita da História, foi possível reconhecer que a Educação Física em Belo Horizonte, nesse período, esteve fortemente conectada aos preceitos morais católicos, além de ter vínculos com as instituições médica e militar, já recorrentemente confirmados pela historiografia. Pareceunos digna de consideração a expressiva presença de freiras e padres participando como alunos ou organizando e ministrando palestras e cursos. Como pretendemos discutir neste artigo, a construção de uma Educação Física afiançada por prescrições e práticas religiosas orientou um modelo pedagógico próprio, de contornos moralizadores, que enfatizava uma educação integral e humanista, aspectos comumente destacados por alunos e professores participantes do "certame". Outro elemento de relevo foi a interdependência, disseminada na capital e nas cidades do interior mineiro, entre o fazer pedagógico da Educação Física escolar e aquele realizado em outros espaços educativos, como os clubes, as ruas de recreio e as várias praças de esporte. Também nos ocupamos em mostrar como as Jornadas foram tempo e lugar de circulação de professores oriundos de outros estados, da Europa, da América do Norte, da Ásia, de países latinoamericanos vizinhos, e de exercícios de difusão e transmissão de ideias, conceitos, práticas e valores educacionais ainda pouco explorados na história da Educação Física brasileira da segunda metade do século XX.

Movimento, Porto Alegre, v. 20, n. 4, p. 1499-1521, out./dez. de 2014. 
Figura 1 - Aula com freiras (reportagem sobre a IV Jornada)

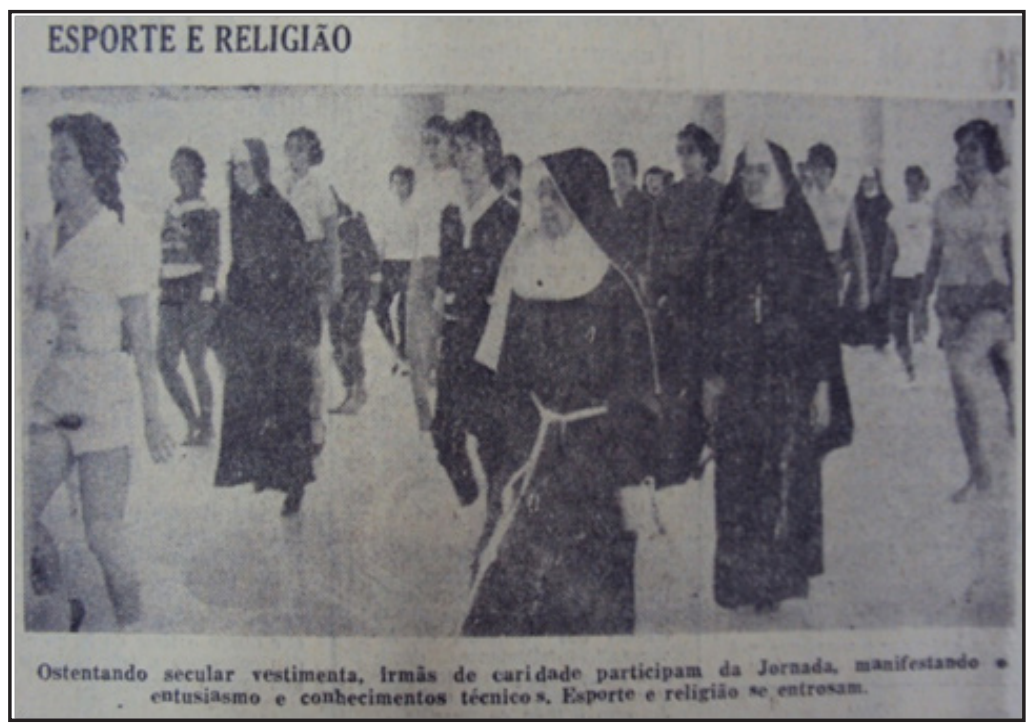

Fonte: Jornal Diário da Tarde, 30 jul. 1960

\section{As CINCO EDIÇÕES DAS JORNADAS INTERNACIONAIS DE Educação Físıca}

Durante o período das Jornadas, os encontros foram realizados anualmente de forma regular, exceção feita ao ano de 1961. Entre os responsáveis pela organização, encontramos a Diretoria de Esportes de Minas Gerais (DEMG), a Escola de Educação Física de Minas Gerais (EEF-MG) e a Associação de Ex-alunos da EEF$\mathrm{MG}$, lugares políticos e institucionais que participaram ativamente da legitimação da Educação Física no Estado. Todas as edições foram nos meses de julho e/ou agosto, anunciadas pelos jornais locais com muita euforia e apresentadas como uma "iniciativa arrojada", sendo os conteúdos ministrados considerados os mais inovadores (ABRE-SE..., 1957).

Em sua primeira edição, o curso foi denominado "Jornada de Estudos de Educação Física", recebendo posteriormente a 
designação de "Jornadas Internacionais de Educação Física", a qual permaneceria até a última edição. O principal objetivo dessa iniciativa era o de trazer "os mais modernos conceitos e métodos" (ABRE-SE..., 1957) produzidos na Educação Física, com o propósito de atualizar conhecimentos de professores e especialistas da área. A cada ano, os alunos vinham de várias regiões de Minas Gerais, de outros estados e até do exterior.

Desde a primeira edição até a quarta, as Jornadas foram apoiadas e patrocinadas pelo governo de Joaquim Francisco Bias Fortes. Político vinculado ao Partido Social Democrático (PSD), governou o Estado entre 1956 e 1961, período no qual exerceu forte influência no âmbito da própria EEF-MG. É interessante o fato de que algumas fontes, como o Jornal Educação Física e as entrevistas concedidas por Fernando Campos Furtado (2011) e Owalder Rolim (2011), mencionem a pessoa do governador e não o Estado, conferindo à relação de Bias Fortes com a Educação Física um caráter personalista. ${ }^{2}$ Ele não somente fornecia recursos financeiros como também participava de algumas solenidades relativas às Jornadas e, em seus discursos, não poupava elogios ao "conclave" e aos organizadores.

Em 1961, já no governo de José de Magalhães Pinto, eleito pela União Democrática Nacional(UDN), o curso não foi realizado. Em seu depoimento, Fernando C. Furtado (2011) chamou de "boicote" a não realização do "certame" daquele ano, como uma espécie de rejeição da nova administração à continuidade do trabalho de seus antecessores. Em 1962, foi organizada a última edição do encontro, já com um formato bastante simples e bem distinto das anteriores. Na ausência de recursos, priorizouse uma programação mais doméstica, com professores de Belo Horizonte. Um dos fatores que podem guardar relação com o fim dessa iniciativa foi a "crise" enfrentada pela Escola de Educação Física no início da década de 1960. Coincidindo com a mudança

${ }^{2}$ As quatro edições do Jornal Educação Física enfatizaram a pessoa do governador Bias Fortes como benfeitor e benemérito da EEF-MG e da Educação Física mineira. Veja também Furtado (2011) e Rolim (2011).

Movimento, Porto Alegre, v. 20, n. 4, p. 1499-1521, out./dez. de 2014. 
de governos, a instituição experimentou problemas políticos e financeiros que fizeram com que se cogitasse até a hipótese de seu fechamento. Suas atividades foram se extinguindo e, provavelmente por isso, a Escola deixou de publicar o Jornal Educação Física (1952-1969) e não mais promoveu as Jornadas Internacionais.

Já no âmbito da DEMG, parecia haver também uma "crise" de outra natureza, relativa a uma querela entre os ditos diplomados e os ditos "leigos", principalmente nas atividades realizadas nas Praças de Esportes, espaços administrados pela DEMG. Nesses locais, antes mesmo da criação da EEF-MG, já havia a presença de instrutores, principalmente oriundos de instituições militares (SILVA, 2009). Owalder Rolim ${ }^{3}$ e Fernando Furtado consideravam a DEMG e seus espaços como o "caminho natural" dos recém-formados pela escola. Para eles, essa instituição era o lugar de colocar em prática o conhecimento adquirido durante o curso superior. Assim, foi instaurada uma campanha dos "técnicos" (formados pela escola) contra os "práticos", que continuavam atuando no ensino. No artigo "Preparação integral para os futuros professores", publicado no Jornal Educação Física (1958), Roberto C. de Queiroz argumentou sobre a importância de os estudantes se empenharem ao máximo em conhecer os aspectos teóricos e práticos da Educação Física e dos esportes. Para ele, os estudantes e os formados em Educação Física tinham de estar cientes de que "se temos um direito legal aos lugares que os 'práticos' ocupam, temos, também, um dever moral, inerente a toda ética profissional, de nos prepararmos não só intelectualmente, mas praticamente para o exercício de nossa profissão" (PREPARAÇÃO..., 1958).

Alterações na diretoria da DEMG, em 1956, também intensificaram as disputas entre "leigos" e "diplomados". O professor Sylvio José Raso foi apontado como o diretor que

${ }^{3}$ ROLIM, Owalder. Belo Horizonte, 6 jun. 2011. Entrevista concedida ao autor. ${ }^{4}$ FURTADO, Fernando Campos. Belo Horizonte, 4 maio 2011. Entrevista concedida ao autor.

Movimento, Porto Alegre, v. 20, n. 4, p. 1499-1521, out./dez. de 2014. 
modificou a política interna desse órgão, constituindo uma equipe de trabalho formada por professores e técnicos, e promovendo diversas atividades, tais como ruas de recreio, torneios, demonstrações de ginástica e cursos de recreação. Antes de sua gestão, as ações ali realizadas limitavam-se a oferecer jogos de camisa aos times de futebol da cidade.

Podemos, assim, considerar que o processo de legitimação profissional da Educação Física envolveu tensões entre técnicos e militares, pois estes últimos, os "práticos", estavam habituados a realizar o ensino de ginásticas e esportes. As alterações administrativas tenderam a beneficiar os "técnicos" formados em curso superior. As fontes consultadas não estabelecem diferenciação entre as expressões "técnico" e "professor" para designarem aqueles que frequentavam o recém-criado Curso Superior em Educação Física.

Assim, ao abordar o contexto de realização das Jornadas, foi preciso considerar as disputas e negociações e o modo como se processou o diálogo em defesa de interesses distintos. Fezse necessário atentar para as lutas de poder e de representação, conforme tais práticas orientaram, no plano cultural, a formação de um imaginário sobre a Educação Física mineira (BACZKO, 1985). Nesse sentido, compreendemos que uma dada organização constitui-se em meio às tramas estabelecidas entre os sujeitos que, por esse modo, estabelecem suas identidades e sentidos de pertencimento a determinado grupo ou prática social em processo de construção (CHARTIER, 1991).

Também nos parece possível afirmar que a realização das Jornadas Internacionais em Belo Horizonte guardava relação com a política mais ampla. O Boletim de Educação Física, informativo da Divisão de Educação Física do Departamento Nacional de Educação Física, apresentou, em dezembro de 1957, uma relação de cursos de aperfeiçoamento técnico e pedagógico para instrutores e professores de Educação Física realizados em diversos estados brasileiros, durante a década de 1950. Entre

Movimento, Porto Alegre, v. 20, n. 4, p. 1499-1521, out./dez. de 2014. 
os professores convidados para alguns desses cursos constam Alfredo Colombo, então diretor da Divisão de Educação Física, e também Auguste Listello (França) e Gerhard Schimidt (Áustria), que estiveram presentes nas Jornadas mineiras. Tais aspectos indiciam um investimento em escala mais ampla, fazendo circular em diferentes regiões do Brasil aqueles sujeitos identificados como divulgadores de metodologias e propostas pedagógicas capazes de renovar e "especializar" o ensino de Educação Física (NOTICIÁRIO..., 1957). ${ }^{5}$

Quanto ao público participante, podemos perceber que, da primeira até a quarta edição, aumentou gradativamente o número de professores da Europa, da Ásia e das Américas do Sul e do Norte convidados para ministrar cursos. Isso também aconteceu com os alunos ou "estagiários" que vieram de países vizinhos (Argentina, México, Japão, Uruguai, Paraguai, Equador), de estados como São Paulo, Rio de Janeiro, Pará, Rio Grande do Sul, Espírito Santo e de muitas cidades do interior de Minas Gerais. Essa diversidade, quando ressaltada pelos jornais, produz representações sobre os eventos com o propósito de realçar, recorrentemente, a abrangência, a qualidade e a originalidade do trabalho realizado. Talvez como uma particularidade mineira, nota-se também a expressiva presença de participantes religiosos, noticiada na imprensa periódica como uma possibilidade concreta de consorciar o desenvolvimento da Educação Física aos preceitos de uma educação moral e de um aperfeiçoamento do espírito.

Além das atividades pedagógicas no formato de cursos, havia também outras atividades de recreação e interação social durante as Jornadas, tais como homenagens, visitas a outras cidades, noites de confraternização, bailes e, ainda, a organização de ruas de recreio envolvendo crianças e jovens no encerramento dos trabalhos das Jornadas Internacionais de 1958, 1959 e 1960. Esses momentos eram considerados propícios para que

${ }^{5}$ Boletim fornecido pelo Centro de Memória da Educação Física, do Esporte e do Lazer (CEMEF/UFMG). Arquivos Pessoais de Professores. Fundo Nella Testa Taranto.

Movimento, Porto Alegre, v. 20, n. 4, p. 1499-1521, out./dez. de 2014. 
os alunos colocassem em prática o que haviam aprendido. Aqui evidenciamos variadas estratégias de ensino e formação docente que, ao serem adotadas, funcionavam também como momentos de integração entre os participantes e como possibilidade de visibilidade pública e política da Educação Física no Estado.

Nos depoimentos, esse tema também aparece recorrentemente. Para José Atayde Lacerda, ${ }^{6}$ o mais importante legado deixado pelos cursos foi o intercâmbio de experiência, "Essa troca de informações [...] Ah! Era muito grande, muito boa"7. Em entrevista, Owalder Rolim ${ }^{8}$ ressaltou indícios de uma apropriação desses saberes em sua prática docente. Falou sobre a diversificação nos conteúdos e o acesso ao conhecimento de novos materiais didáticos, comentando seu uso posterior ao curso. Fernando Campos Furtado ${ }^{9}$ também relembrou as aulas, especialmente as do professor austríaco Gerhard Schimidt, afirmando que utilizou, durante sua carreira, os jogos aprendidos nessa ocasião, pois, segundo ele, o curso oferecia "processos pedagógicos que ficavam".

Durante a III Jornada, o Jornal Diário de Minas, em 31 de julho de 1959, anunciou: "Participantes nacionais e estrangeiros procuram tirar o melhor proveito do certame promovido pela Diretoria de Esportes”. E acrescentou: “Gente do país e do exterior à procura de melhores conhecimentos em assuntos esportivos e de educação física veio juntar aos inscritos da capital, formando um agrupamento de 450 pessoas". O Jornal também informava que, nas aulas teóricas e práticas, haveria cobrança de presença obrigatória, assim como nas palestras, exibições de filmes e demonstrações. Para a aluna argentina Aurora Bugiolacchi, a

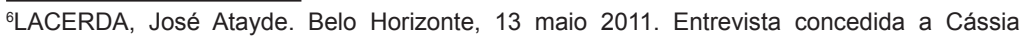
Danielle M. D Lima.

${ }^{7}$ LACERDA, José Atayde. Belo Horizonte, 13 maio 2011. Entrevista concedida a Cássia Danielle M. D Lima.

${ }^{8}$ ROLIM, Owalder. Belo Horizonte, 6 jun. 2011. Entrevista concedida a Cássia Danielle M. D Lima.

${ }^{9}$ FURTADO, Fernando Campos. Belo Horizonte, 4 maio 2011. Entrevista concedida a Cássia Danielle M. D Lima.

Movimento, Porto Alegre, v. 20, n. 4, p. 1499-1521, out./dez. de 2014. 
carga horária do curso era muito extensa e sua programação pouco flexível. Essa aluna fez parte de uma delegação argentina de 30 professores, sob a direção do Dr. Ramon Muros, diretor da Escola de Educação Física “daquele país amigo” (TÉCNICA..., 1959). Vale ressaltar que, nesse mesmo período, muitos professores mineiros também participaram de eventos relativos à Educação Física na Argentina, indiciando uma rede de trocas entre os dois países, ainda pouco explorada pela historiografia da Educação Física brasileira.

O termo "moderno" foi amplamente utilizado na perspectiva de oposição ao antigo, como um exercício de ruptura com o passado e como um propósito de promoção presente. Utilizado recorrentemente nos anúncios jornalísticos e nos discursos dos professores, o "moderno" se aproximava das discussões presentes no campo educacional brasileiro na década de 1950. Segundo Josildeth Consorte (1997, p. 3), "É dessa época a percepção do país como dois Brasis, um arcaico, tradicional, e outro moderno, e a crença em que o desenvolvimento de sua porção moderna levaria à superação de suas contradições, fazendo-o, finalmente, dar o tão esperado salto para o futuro".

Entretanto, o "moderno" que chegava às Minas Gerais, vindo de diferentes lugares, passaria pelo crivo da tradição. Conciliando modernidade e tradição, as Jornadas cumpriram seu propósito de interrogar a Educação Física realizada no Brasil, cotejando-a com aquela em curso nos países da Europa. Nas fontes analisadas, algumas vezes foi atribuído ao nosso país o status de atrasado e aos países europeus a referência do avanço. Com tais características e sob tais condições, as várias edições anuais concretizaram o propósito de dar visibilidade e legitimidade à formação de professores de Educação Física.

Movimento, Porto Alegre, v. 20, n. 4, p. 1499-1521, out./dez. de 2014. 
Sujeitos, saberes e práticas em circulação nas Jornadas...

Figura 2 - Professor Gerhard Schimidt e alunos durante a III Jornada Internacional de Educação Física

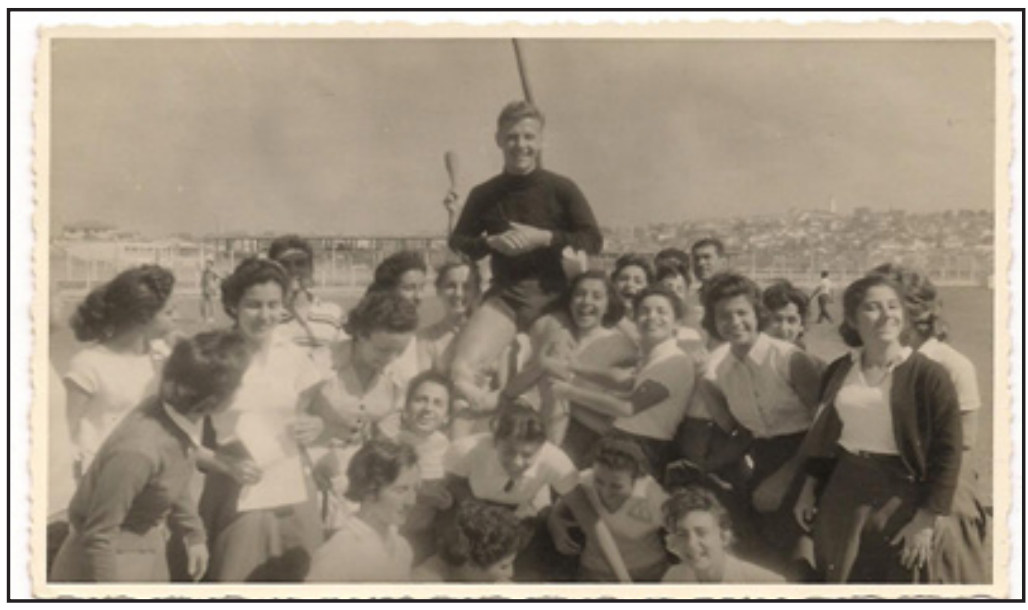

Fonte: Acervo do CEMEF/UFMG. Coleção Iconográfica (Jornadas).

\section{Conteúdos e saberes em CIRCulaÇÃo nos tempos e ESPAÇOS DO CERTAME}

Conteúdos variados circularam nas Jornadas, dando a ver que a Educação Física brasileira do período agregava um amplo repertório de temas e práticas que eram identificados como legítimos para o seu ensino e para a formação de seus professores. Alguns cursos ministrados estiveram diretamente atrelados à composição de aulas e programas de ensino, e abordaram, entre outros, as ginásticas, os esportes, as danças, os jogos infantis. Outros versaram sobre temas ligados ao cotidiano da docência, à legislação vigente, aos princípios orientadores daquela que seria a boa conduta esperada dos professores.

Identificamos forte presença do conteúdo ginástica, representada nas cinco edições por uma gama de adjetivos: sueca, geral, moderna, educativa, acrobática, infantil, austríaca, etc. Também foram ministrados cursos de modalidades esportivas

Movimento, Porto Alegre, v. 20, n. 4, p. 1499-1521, out./dez. de 2014. 
individuais e coletivas (basquetebol, voleibol, atletismo, natação, futebol de salão, handebol, etc.). Nota-se uma ênfase para os jogos de quadra, sempre mais frequentes do que as modalidades identificadas como "individuais". Do conteúdo danças, a maioria dos cursos foi sobre as folclóricas (estrangeiras e brasileiras) e as escolares. Também encontramos as danças presentes como atividades integrantes de outros temas, como recreação, jogos infantis e ginásticas.

As práticas esportivas foram ganhando, gradativamente, mais espaço no decorrer das cinco edições das Jornadas, com diferenças no modo de abordá-las. Na primeira, apenas o professor Moacyr Daiuto, no caderno de planejamento do basquetebol, discorreu sobre o assunto, abordando questões táticas, técnicas e sociais. No caderno de planejamentos que tratou das modalidades handebol, futebol de salão e voleibol, os conteúdos tinham caráter mais informativo, enfatizando regras e técnicas relativas a esses esportes. Já os Anais da V Jornada apresentaram textos nos quais os professores evidenciavam maior atenção às questões de ordem moral e social, destacando princípios educativos como orientadores no ensino de regras e fundamentos das modalidades. Outra preocupação da maioria dos docentes foi com o aprendizado prazeroso. Esperava-se que o ensino de Educação Física incutisse nos jovens o desejo de praticar os esportes, mesmo sem a presença de um professor.

Nos cadernos de planejamento sistematizados pelos professores para os cursos foi possível notar que, muitas vezes, os papéis de "professor" e "técnico" se misturavam, não obtendo distinção clara. Quando se referiam ao aluno, faziam menção principalmente à criança ou ao esportista/jogador, na maioria das vezes, utilizando a palavra no gênero masculino (o aluno, o esportista, o jogador). Parece-nos que a diferenciação mais enfatizada era apenas etária. Porém não havia consenso nas recomendações dos docentes acerca da idade de ingresso na iniciação esportiva. Alguns defendiam que a criança ingressasse no esporte a partir de 4-6 anos; outros, a partir dos 10 .

Movimento, Porto Alegre, v. 20, n. 4, p. 1499-1521, out./dez. de 2014. 
Quanto à questão de gênero, na primeira edição, somente nas temáticas sobre danças e ginástica feminina os sujeitos eram tratados no gênero feminino. Já na $V$ Jornada, há uma constante referência à presença da mulher nos esportes coletivos, acrescida da ênfase dos professores em afirmar que a prática de esportes não alteraria os atributos ditos femininos: "a leveza", "a plasticidade", "a harmonia". Nas cinco edições, enquanto podemos observar os homens no comando de atividades com temáticas variadas, como cursos de recreação, danças folclóricas, ginástica, jogos e diversas modalidades esportivas, identificamos que as mulheres ficaram a cargo das atividades relacionadas com a dança, os jogos infantis e principalmente com a ginástica e suas ramificações. Ou seja, uma presença masculina autorizada a transitar pelos diversos conteúdos e práticas, e uma presença feminina limitada ao universo da infância e dos exercícios harmônicos, leves e suaves. Todavia, embora a participação das professoras ficasse restrita a esses temas, o tempo destinado aos seus cursos ocupava aproximadamente $50 \%$ da carga horária dos cursos.

Na maioria das vezes, o conteúdo proposto para os cursos era anunciado por meio da exaltação do nome dos professores ministrantes, os quais recebiam designações como "grande mestre", "grandes expressões", "nome por demais consagrado". No quadro 1, apresentamos alguns desses professores e o tema dos cursos que ministraram.

Movimento, Porto Alegre, v. 20, n. 4, p. 1499-1521, out./dez. de 2014. 
Quadro 1 - Professores referenciados nos jornais e respectivos cursos ministrados

\begin{tabular}{|c|c|c|}
\hline Professor(a) & $\begin{array}{l}\text { País de } \\
\text { origem }\end{array}$ & Curso ministrado \\
\hline Gerhard Schimitd & Áustria & $\begin{array}{l}\text { Método natural austríaco e } \\
\text { ginástica geral }\end{array}$ \\
\hline Hanns Prochowinck & Brasil (RJ) & Ginástica de solo \\
\hline August Listello & França & Atividades físicas generalizadas \\
\hline $\begin{array}{c}\text { Antônio Boaventura } \\
\text { da Silva }\end{array}$ & Brasil (SP) & Ginástica sueca \\
\hline Moacyr Daiuto & Brasil (SP) & Basquetebol \\
\hline Pierre Weil & Brasil & $\begin{array}{l}\text { Psicologia aplicada à Educação } \\
\text { Física }\end{array}$ \\
\hline Gino Poiani & Itália & Atletismo - arremesso de peso \\
\hline Dorle Drewke Kuck & Alemanha & Ginástica feminina \\
\hline $\begin{array}{c}\text { Joaquim Lacaz de } \\
\text { Morais }\end{array}$ & Brasil (SP) & $\begin{array}{l}\text { Fisiologia aplicada; fisiologia da } \\
\text { emoção; controles nervosos do } \\
\text { aparelho locomotor; biotipologia } \\
\text { da Educação Física }\end{array}$ \\
\hline Lia Bastian Meyer & Brasil (RS) & Ginástica rítmica \\
\hline $\begin{array}{l}\text { João Carlos Paixão } \\
\text { Côrtes }\end{array}$ & Brasil (RS) & Danças regionais \\
\hline Érica Saur & Brasil (RJ) & Ginástica feminina \\
\hline $\begin{array}{c}\text { Yesis Ilda y } \\
\text { Amoedo Passarinho }\end{array}$ & Brasil (RJ) & Sociometria \\
\hline Hélcio Buck Silva & Brasil (PR) & Circuit training \\
\hline Alfonz Z. Renez & Hungria & $\begin{array}{l}\text { Educação Física para crianças; jogos } \\
\text { e atividades com e sem aparelhos }\end{array}$ \\
\hline
\end{tabular}

Fonte: Lima (2012, p. 183-188).

De acordo com os programas elaborados para cada Jornada, podemos inferir que os organizadores almejavam oferecer aos participantes saberes variados que incluíssem pormenores sobre as dimensões técnicas de cada atividade e que fossem apreendidos como saberes científica e pedagogicamente sistematizados. 
Sujeitos, saberes e práticas em circulação nas Jornadas...

Tais referências estavam recorrentemente vinculadas ao desenvolvimento moral e ao papel conferido à Educação Física no desenvolvimento das relações humanas. As fontes nos permitem indiciar intencionalidades formativas nessas escolhas, coerentes com os princípios que os organizadores acreditavam ser os melhores. Nesses termos, ao selecionarem conteúdos a serem ensinados e docentes convidados para ministrá-los, realizavam uma clara seleção de valores e normas educacionais (HÉBRARD, 1990).

Uma Educação Física que abarcasse as questões morais foi uma preocupação que perpassou a maioria dos conteúdos e esteve diretamente ligada aos preceitos católicos. Educando as vontades, reprimindo a agressividade, direcionando a motivação, a Educação Física contribuiria na formação integral dos sujeitos que, assim educados, trariam benefícios para a sociedade. Como anunciou o governador Bias Fortes, em 1958, ao ressaltar a plena confiança que depositava na formação oferecida pela EEF-MG, o trabalho em curso era uma "garantia do elevado padrão de ensino e da rígida orientação moral, dentro dos mais sadios princípios cristãos, que asseguram a plena conquista dos objetivos colimados por todos os mineiros" (O COROAMENTO..., 1958). As premissas do governador foram endossadas pelo padre Carlos José Gonçalves, professor de Cultura Religiosa e de Antropologia, em palestra ministrada na II Jornada:

Quando dizemos MORAL, estamos querendo exatamente dizer, Moral Religiosa, moral que vem de Deus e que é encaminhamento para Deus. Moral sem religião é balela. Não tem direito de existir, porque é moral mentirosa, falsa em seus princípios, perniciosa em suas consequências $(\mathrm{O}$ COROAMENTO..., 1958) (grifo do autor).

$\mathrm{Na}$ aula inaugural da III Jornada, ministrada pelo então bispo auxiliar de Belo Horizonte, Dom Serafim Fernandes de Araújo, a ligação entre religião e Educação Física foi ressaltada mais uma vez e os pontos por ele destacados se assemelharam ao discurso proferido pelo Papa Pio XII, em 8 de novembro de 1952 (PIO XII, 1952). Dom Serafim dissertou sobre a "dignidade

Movimento, Porto Alegre, v. 20, n. 4, p. 1499-1521, out./dez. de 2014. 
do corpo", expondo as diferenças entre a concepção materialista e o pensamento cristão: "A máxima é esta: cuidado do corpo, sim; culto do corpo, divinização do corpo, não [...] o espírito ocupa o primeiro lugar e não o corpo" (RELIGIÃO..., 1958). Argumentou ainda ser um erro considerar o esporte ou a Educação Física como um fim em si mesmo, devendo sua prática ser considerada um meio.

As Jornadas realizadas em Belo Horizonte pareciam modelar a Educação Física como uma disciplina comprometida com os preceitos da moral cristã, devendo os docentes zelar pelo "espírito" de seus alunos. Como orientava o Pe. Carlos: "Entre dois atletas que disputam na pista, pode ser um mais atleta. Mas, não será mais $H O M E M$ se não tiver sabido aliar ao contingente de músculos o vigor de alma" (CORPUS..., 1957) (grifo do autor).

Apesar de a maioria dos mestres terem se apoiado em preceitos cristãos para salientarem a importância moral da Educação Física, encontramos outro foco nos argumentos do professor Albano Augusto Pinto Corrêa Filho, mais vinculado à noção de civilidade. Para ele, os professores deveriam atentar para a educação cívica dos sujeitos, pois só assim formariam pessoas à altura de mártires como Tiradentes e gênios como Santos Dumont. Justificou, também, que suas aulas não estavam relacionadas à lógica "militarista", mas sim ao desejo de que seus alunos se tornassem "bons professores, respeitados na profissão que escolheram” (DISCIPLINA..., 1958).

Também os argumentos relativos a uma educação integral ecoaram de modo recorrente nas Jornadas, reafirmando princípios já em voga na Educação Física em décadas anteriores. Para o professor húngaro Afonz Renez (1957), a Educação Física escolar não tinha a responsabilidade de formar atletas, mas sim "dar uma base": o "educador tem a grande obrigação de formar o pequeno na sua totalidade". Já o professor austríaco Gerhard Schimidt enfatizou a importância do exercício "guiado pedagogicamente", pois o resultado seria sempre positivo e permearia "os aspectos orgânico, intelectual, moral e espiritual” (MÉTODO..., 1957).

Movimento, Porto Alegre, v. 20, n. 4, p. 1499-1521, out./dez. de 2014. 
A ênfase parecia estar em pensar uma Educação Física sem dicotomias e voltada para as necessidades da criança. Para Moacyr Daiuto, assim como para Luiz Mattos, Guiomar M. Becker e Afonz Renez, o educador deveria desenvolver harmonicamente a personalidade dos alunos; não somente prezar pela eficiência, mas também pela formação emocional e intelectual do indivíduo, integrando-o socialmente. Para balizar seus argumentos, os professores afirmaram que essa disciplina, devido a suas singularidades, era capaz de interferir no corpo físico, na mente, na moral e no espírito com mais eficiência que as demais.

Nos cursos focados nas modalidades esportivas, os docentes expuseram vários conselhos aos professores sobre a importância da conduta pessoal do técnico na formação dos alunos e também sobre a formação moral do atleta. São recomendações que vão desde a atenção à luminosidade do local da aula até aquelas que sugerem como responsabilidade do professor estabelecer um "espírito de camaradagem" entre os alunos, ensinando-os a respeitar os juízes e a não usarem de meios escusos para alcançar a vitória. Uma longa lista de orientações didáticas carregadas de preocupação com a formação humana. Segundo o professor Adolfo Guilherme:

Para se formar uma grande equipe, não basta reunir uma turma que saiba jogar VOLEIBOL. É necessário também ampliar as qualidades morais do atleta e instruí-lo no sentido de conduzir durante o treinamento de modo a se adaptar mais facilmente dentro da equipe. São outras qualidades que precisam ser desenvolvidas no atleta, além da correta execução dos fundamentos: a noção de cumprimento do dever - frequência, pontualidade, etc.; CAVALHEIRISMO; saber VENCER e saber PERDER; possuir AMOR PRÓPRIO para reagir quando estiver sendo SUPERADO; dominar o SISTEMA NERVOSO para não perturbar a HARMONIA da equipe e não influir em seu descontrole; saber despertar no companheiro o PRAZER de jogar voleibol ao seu lado [...] compreender que é IMPOSSÍVEL formar uma grande equipe com jogadores MEDÍOCRES (GUILHERME, A., jul. 1962) (grifos do autor).

Movimento, Porto Alegre, v. 20, n. 4, p. 1499-1521, out./dez. de 2014. 
Esses, entre outros tantos códigos e princípios educativos, circularam nas Jornadas Internacionais, ampliando o entendimento sobre a Educação Física, mesmo que, para muitos professores, a educação se apresentasse como uma ação de transmissão de conteúdo e valores. E, por mais que atribuíssem à Educação Física a função de formar o sujeito "em sua totalidade", o professor Pedro Rodrigues advertiu que o docente dessa disciplina não poderia resolver, por si, o problema da educação inteiramente. O professor Afonz Renez (1957) argumentou sobre a necessidade das várias disciplinas escolares se aliarem, atuando "como engrenagens de máquinas".

Figura 3 - Caderno de planejamento da I Jornada. Atividades Físicas Generalizadas (professor Auguste Listello, ago. 1957)

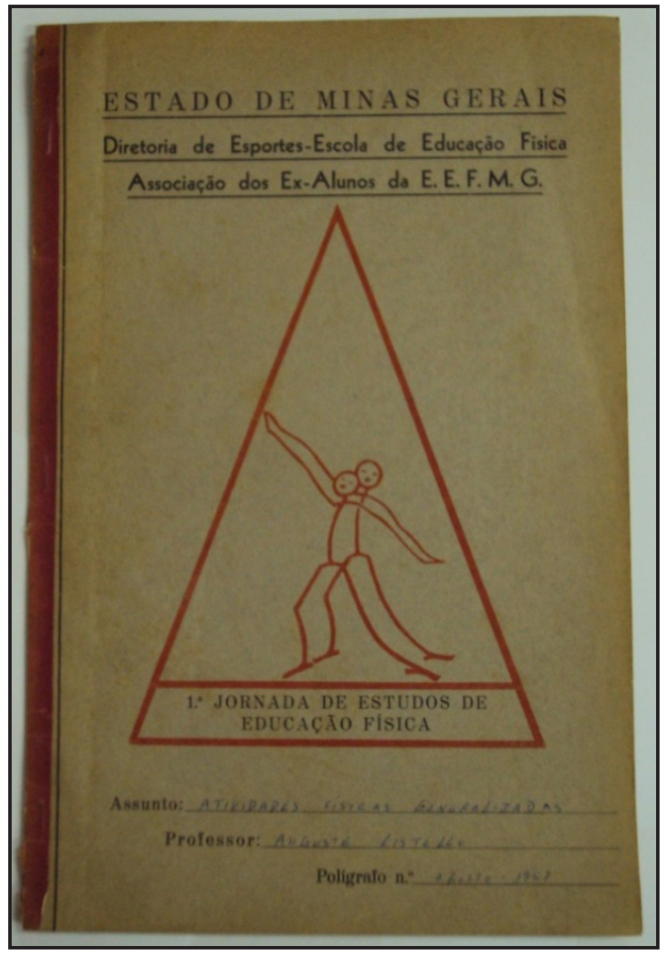

Fonte: Acervo do CEMEF/UFMG. Fundo Institucional E.E.F.M.G.

Movimento, Porto Alegre, v. 20, n. 4, p. 1499-1521, out./dez. de 2014. 


\section{OUtras Jornadas}

O estudo realizado nos permite afirmar que, na formação oferecida pelas Jornadas, houve forte integração de conteúdos, de sujeitos e de práticas, em permanente processo de negociação de valores e ideais pedagógicos. Nas décadas de 1950 e 1960, os professores de Educação Física insistiram em relacionar conteúdos biológicos e sociais, defendendo uma correlação entre eles e apostando em uma formação integral do aluno ou em um processo formativo "psico-socio-morfo-fisiológico", como gostavam de nomear. Também foi possível perceber que havia uma grande interação entre os sujeitos envolvidos com as aulas: uma interação corporal, de confiança, respeito e solidariedade. Identificamos também uma integração entre alunos e professores na execução das atividades.

Tanto nas fontes escritas quanto nas entrevistas realizadas, apreendemos uma vontade latente de "fazer dar certo". No percurso profissional de cada um dos sujeitos participantes, talvez seja possível identificar processos de apropriação cultural dos saberes que foram apresentados e praticados nas Jornadas. Embora tal movimento investigativo escape aos propósitos deste estudo, as fontes mobilizadas nos permitem indicar tal hipótese.

Outro aspecto a considerar é a ênfase no que vinha de fora, sobretudo no que era produzido em outros países, representado como bom, "moderno", "evoluído". Isso se torna mais complexo no discurso do professor austríaco Gerhard Schimidt, que afirmou a importância da Educação Física na formação da juventude, ressaltando que, no Brasil, isso era mais evidente, uma vez que "há uma raça em formação" (MÉTODO..., 1957). Tal discurso guarda relação com a crença em um Brasil arcaico, atrasado e de um povo frágil e inculto. Como ressalta Marcos Freitas (2010, p. 36), "Um país sempre próximo da modernidade, mas nunca plenamente dentro dela". Identificamos, assim, no âmbito da Educação Física, questões maiores de um debate de várias décadas sobre a constituição do povo brasileiro.

Movimento, Porto Alegre, v. 20, n. 4, p. 1499-1521, out./dez. de 2014. 
Quanto aos aspectos metodológicos, notamos que as entrevistas concedidas pelos professores Fernando Campos Furtado ${ }^{10}$, José Atayde Lacerda ${ }^{11}$ e Owalder Rolim ${ }^{12}$ foram essenciais na construção desta narrativa. Protagonistas dessa trama, não são mais os mesmos, e o modo como olham para o passado condiz com os ideais que acreditam no presente. Entretanto o nosso intuito foi o de enfatizar o que escolheram perpetuar, como nos ensina Ecléa Bosi (2003). Essa preocupação orientou o esforço para que cada pista fosse valorizada como informação importante. Nosso intuito foi o de qualificar a análise e a problematização das fontes, assim como a narrativa dessa história.

Vários assuntos abordados no âmbito das Jornadas parecem ainda presentes no fazer cotidiano da Educação Física nas escolas: os jogos como importantes meios de formação da criança, o viés recreativo das aulas, a relevância de certos atributos físicos para a prática de algumas modalidades esportivas, a falta de material e espaços específicos nas escolas, a forma de planejar e organizar a aula, entre outros. Ao constatar tais permanências, ponderamos que não se trata de uma "expressão de inércia ou mera reprodução histórico-cultural" (LINHALES, 2006, p. 246). Antes, tais fatos reforçam o entendimento de que a história da formação de professores de Educação Física e das práticas de ensino adotadas em Minas Gerais será mais bem compreendida com estudos que abarquem a longa duração e que sejam capazes da indicar os sentidos conferidos às rupturas e às continuidades.

Refletindo sobre a formação de professores de Educação Física no tempo presente, nós nos indagamos: ficamos nós, professores e alunos de Educação Física, "mais pobres em experiências comunicáveis, e não mais ricos”? (BENJAMIN, 1987, p. 114). O

${ }^{10}$ FURTADO, Fernando Campos. Belo Horizonte, 4 maio 2011. Entrevista concedida a Cássia Danielle M. D. Lima.

${ }^{11}$ LACERDA, José Atayde. Belo Horizonte, 13 maio 2011. Entrevista concedida a Cássia Danielle M. D. Lima.

${ }^{12}$ ROLIM, Owalder. Belo Horizonte, 6 jun. 2011. Entrevista concedida a Cássia Danielle M. D. Lima.

Movimento, Porto Alegre, v. 20, n. 4, p. 1499-1521, out./dez. de 2014. 
professor Owalder Rolim ${ }^{13}$ compartilhou impressões similares ao manusear documentos durante sua entrevista: "É engraçado... em vez das coisas evoluírem, elas, de vez em quando, somem”.

Subjects, knowledge and practices circulating in International Meetings of Physical Education: pedagogical textures and models (Belo Horizonte, 1957-1962)

Abstract: This article discusses, from a historical perspective, physical education training teachers based on methods, contents and subjects circulating in International Meetings of Physical Education held in Belo Horizonte from 1957 to 1962. Using written sources and statements, it identified a physical education with moralizing features, based on religious prescriptions, indicating the precepts of an integral and humanistic education.

Keywords: Physical Education history. Teacher training. Pedagogical models.

Sujetos, saberes y prácticas en circulación en las Jornadas
Internacionales sobre Educación Física: tesituras y modelos
pedagógicos (Belo Horizonte, 1957-1962)
Resumen: Este artículo aborda, desde una perspectiva histórica, la
temática de la formación de profesores en Educación Física, a partir
de analizar los métodos, contenidos y sujetos que participaron en
las Jornadas Internacionales de Educación Física, desarrolladas en
la ciudad de Belo Horizonte (Brasil) entre 1957 y 1962. La reflexión
sobre las fuentes documentales y discursos sobre estos eventos
reflejan lo que puede identificarse como una Educación Física de
contornos moralizadores, amparada en prescripciones religiosas
que destacaban preceptos que procuraban una educación integral
y humanista.
Palabras clave: Historia de la Educación Física. Formación de
profesores. Modelos pedagógicos.

${ }^{13}$ ROLIM, Owalder. Belo Horizonte, 6 jun. 2011. Entrevista concedida a Cássia Danielle M. D. Lima.

Movimento, Porto Alegre, v. 20, n. 4, p. 1499-1521, out./dez. de 2014. 


\section{REFERÊNCIAS}

ABRE-SE nova etapa do ensino da Educação Física em Minas. Jornal Educação Física, Belo Horizonte, v. 1, n. 1, out. 1957.

BACZKO, Bronislaw. Imaginação Social. In: ENCICLOPÉDIA Einaudi: AntroposHomem. Lisboa: Imprensa Nacional, 1985.

BENJAMIM, Walter. Experiência e pobreza. In: BENJAMIM, Walter. Obras escolhidas, 1: magia e técnica, arte e política. São Paulo: Brasiliense, 1987.

BOSI, Ecléa. O tempo vivo da memória: ensaios de psicologia social. Cotia: Ateliê, 2003.

CHARTIER, Roger. O mundo como representação. Revista Estudos Avançados, São Paulo, v. 5, n. 11, p. 173-191, jan./abr. 1991.

CONSORTE, Josildeth G. Culturalismo e educação nos anos 50: o desafio da diversidade. Cadernos Cedes, Campinas, v. 18, n. 43, p. 26-37, 1997.

CORPUS sanum in mente sana. Jornal Educação Física, Belo Horizonte, v. 1, n. 1, out. 1957.

DISCIPLINA: alicerce de uma geração vigorosa. Jornal Educação Física, Belo Horizonte, v. 2, n. 2, jan. 1958.

FREITAS, Marcos Cezar de. Os temas História e Religião na configuração dos debates sobre as reformas educacionais das décadas de 1950 e 1960: a singularidade de uma situação-pessoa. In: FARIA FILHO, L. M.; NASCIMENTO, C. V.; SANTOS, M. L. Reformas educacionais no Brasil: democratização e qualidade da escola pública. Belo Horizonte: Mazza, 2010.

GUILHERME, Adolfo. Iniciação Esportiva em Voleibol. In: JORNADAS INTERNACIONAIS DE EDUCAÇÃO FÍSICA. 5., jul. 1962, Belo Horizonte. Anais... Belo Horizonte: Escola de Educação Física de Minas Gerais, 1962.

HÉBRARD, Jean. A escolarização dos saberes elementares na época moderna. Teoria \& Educação, Porto Alegre, n. 2, p. 65-109, 1990.

LIMA, Cássia D. M. D. Ensino e formação: os mais modernos conceitos e métodos em circulação nas Jornadas Internacionais de Educação Física (Belo Horizonte, 1957 - 1962)". Dissertação (Mestrado em História da Educação). Faculdade de Educação da UFMG, Belo Horizonte, 2012.

LINHALES, Meily Assbú. A escola, o esporte e a energização do caráter: projetos culturais em circulação na Associação Brasileira de Educação (1925-1935). Tese (Doutorado em História da Educação). Faculdade de Educação da UFMG, Belo Horizonte, 2006.

MÉTODO revolucionário de Educação Física. Jornal Educação Física, Belo Horizonte, v. 1, n. 1, out. 1957.

Movimento, Porto Alegre, v. 20, n. 4, p. 1499-1521, out./dez. de 2014. 
Sujeitos, saberes e práticas em circulação nas Jornadas...

NOTICIÁRIO da Divisão de Educação Física. Boletim de Educação Física, Belo Horizonte, v. 6, n. 15, dez. 1957. Comemorativo do $20^{\circ}$ Aniversário da DEF.

O COROAMENTO de mais um ano de atividades. Jornal Educação Física, Belo Horizonte, v. 2, n. 2, jan. 1958.

PIO XII (Papa). Discorso di Sua Santità Pio XII ai partecipanti al Congresso Scientifico Nazionale Italiano dedicato alle Attività Ginnico-sportive. Roma, 8 nov. 1952. Disponível em: <http://www.vatican.va/holy father/pius xii/ speeches/1952/documents/hf_p-xii_spe_19521108_gran-cuore_it.html>. Acesso em: 29 abr. 2014.

PREPARAÇÃO integral para os futuros professores. Jornal Educação Física, Belo Horizonte, v. 2, n. 3, nov. 1958.

RELIGIÃO e esporte. Jornal Educação Física, Belo Horizonte, v. 2, n. 2, jan. 1958.

RENEZ, Afonz. Educação Física para crianças. In: JORNADA DE ESTUDOS DA EDUCAÇÃO FÍSICA, 1., ago. 1957, Belo Horizonte. Caderno de planejamento. Belo Horizonte: Escola de Educação Física de Minas Gerais, 1957.

SILVA, Giovanna Camila da. A partir da Inspetoria de Educação Física de Minas Gerais (1927-1937): movimentos para a escolarização da Educação física no Estado. 2009. 228 f. Dissertação (Mestrado em História da Educação) - Faculdade de Educação, Universidade Federal de Minas Gerais, Belo Horizonte, 2009.

TÉCNICA argentina sugere: cursos esportivos deverão ser incluídos nas próximas temporadas. Jornal Folha de Minas, Belo Horizonte, 25 jul. 1959.

THOMPSON, Alistair; FRISCH, Michael; HAMILTON, Paula. Os debates sobre memória e história: alguns aspectos internacionais. In: AMADO, Janaína; FERREIRA, Marieta de Moraes (Org.). Usos e abusos da história oral. 5. ed. Rio de Janeiro: FGV, 2002, p. 65-92.

Recebido em: 29.04.2014

Aprovado em: 14.06.2014

Movimento, Porto Alegre, v. 20, n. 4, p. 1499-1521, out./dez. de 2014. 